\title{
A NOVEL AND FACILE METHOD FOR SILICA NANOPARTICLES SYNTHESIS FROM HIGH TEMPERATURE VULCANIZATION (HTV) SILICONE
}

\author{
Mohammad Senemar $^{1}$, Ali Maleki ${ }^{2 *}$, Behzad Niroumand ${ }^{1}$, \\ Alireza Allafchian ${ }^{3}$ \\ ${ }^{1}$ Department of Materials Engineering, Isfahan University of Technology, \\ Isfahan, 84156-83111, Iran \\ ${ }^{2}$ Steel Institute, Isfahan University of Technology, Isfahan, 84156-83111, Iran \\ ${ }^{3}$ Nanotechnology and Advanced Materials Institute, Isfahan University of \\ Technology, Isfahan, 84156-83111, Iran
}

Received 30.09.2015

Accepted 17.02.2016

\begin{abstract}
This study is introducing a facile and novel method for synthesis of amorphous silica nanoparticles. Silica nanoparticles were synthesized by pyrolysis and combustion of high temperature vulcanization (HTV) silicone at $700{ }^{\circ} \mathrm{C}$ for $1 \mathrm{~h}$. The products were investigated employing transmission electron microscopy (TEM), field emission scanning electron microscopy (FESEM), dynamic light scattering (DLS), X-ray diffraction (XRD), Brunauer Emmett and Teller (BET) test and Fourier Transform Infrared (FTIR) Spectroscopy. The results indicated that the method is capable of synthesis of amorphous silica nanoparticles with sizes of mostly between 10 and $50 \mathrm{~nm}$. Keywords: silica nanoparticles, pyrolysis, combustion, HTV silicone, organic material
\end{abstract}

\section{Introduction}

Demand for nanoparticles is growing with advance of science and technology. These nanoparticles are used in several areas such as optoelectronics, catalysis, micro electronics, information storage, etc. [1-3]. Production of silica nanoparticles for use in catalysts, semiconductors, thermal insulators, glass, ceramic and concrete is taken into consideration in the last decade [4-8]. They are also used as drug carriers in pharmaceutical industry due to their large specific surface and high biocompatibility [9, 10]. Silica is a polymer of silicic acid consisting of interlinked $\mathrm{SiO}_{4}$ units in a tetrahedral fashion with the general formula $\mathrm{SiO}_{2}$. Naturally occurring silica is

*Corresponding author: Ali Maleki, maleki110@cc.iut.ac.ir 
crystalline and exists as sand, glass, quartz, etc., whereas synthetic silica is amorphous. Most nanoparticles synthesis techniques, such as physical vapor deposition, precipitation and sol-gel methods are expensive and complex and offer only limited control over particle size and size uniformity [10-14]. Silica nanoparticles are often produced using chemical methods such as sol-gel and deposition [15-19]. Adam et al. [15] employed sol-gel method to derive nanosilica from rice husk with an average size of $50.9 \mathrm{~nm}$. Jal et al. [16] produced silica nanoparticles with an average size of about 50 $\mathrm{nm}$ using deposition method. Sol-gel technique has advantages such as homogeneity and high purity. However, it has disadvantages such as long drying times, high shrink age and difficulty in preparing non-oxide ceramics [20].

Recently, more attention has been paid to manufacturing ceramic materials via pyrolysis of polymers. This is due to advantages unachievable by conventional methods such as high purity, processing versatility, lower processing temperature and preparation of metastable phases [21-23]. Pyrolysis is a very important step in the polymerization pyrolysis process for preparation of silicone base inorganic membranes. This process has been used to produce inorganic membranes which are excellent candidates for membrane gas separation at high temperatures [24]. Recent studies have employed this method for production of silica nanoparticles [25-28]. For instance, Gu et al. [25] pyrolysed rice husk after sol-gel treatment to synthesize silica nanoparticles. In their multistage process, pyrolysis is capable of decreasing particles size.

Silicones are class of synthetic compounds, which the molecules consist of polymer chains of alternately connected silicone and oxygen atoms. Typical organic polymer materials consist of carbon atoms linked together whose backbone chain is repeated many hundreds to thousands of times. However, in silicones Si-O siloxane structure makes them chemically different. They are found in a variety of applications with properties ranging from long-life at elevated temperatures to fluidity at low temperatures [29].

In this study, amorphous silica nanoparticles were synthesized through pyrolysis and combustion of high temperature vulcanization (HTV) silicone in a one step process. The process is fast, facile and is able to produce high purity silica nanopowder. The products were then characterized using different characterization techniques.

\section{Experimental procedure}

HTV silicone (KCC Co., South Korea) was procured as the raw material for synthesis of silica particles. The pyrolysis behavior of HTV silicone was investigated by thermogravimetric analysis (TGA) using STA503 WinTA instrument in nitrogen atmosphere at heating rate of $10{ }^{\circ} \mathrm{C} / \mathrm{min}$. Then $10 \mathrm{~g}$ of the silicone was placed in an alumina crucible and heated up with a heating rate of $20^{\circ} \mathrm{C} / \mathrm{min}$ to $700{ }^{\circ} \mathrm{C}$. The material was pyrolyzed and combusted while held at this temperature for one hour. The product was then furnace-cooled. The experimental conditions outlined above were based on a number of preliminary studies.

The combusted and pyrolyzed HTV silicone, were characterized employing Fourier Transform Infrared (FTIR) Spectroscopy. Spectra were obtained within 4000$500 \mathrm{~cm}^{-1}$ range with a resolution of $4 \mathrm{~cm}^{-1}$ on Brucker, Tensor27 device, X-Ray Diffraction(XRD) analysis (Philips, X'pert with copper in the range of $10-90^{\circ}$ and speed of $0.05^{\circ} / \mathrm{min}$ ) and field emission scanning electron microscope (FESEM) (Hitachi, 4160 S). To clarify the nanoscale structure, transmission electron microscope (TEM) (Zeiss, 
EM10C) was also used at an accelerating voltage of $100 \mathrm{kV}$. For TEM sample preparation, nanoparticles were suspended in water and a small drop of the suspension was deposited on the carbon coated copper grid. Size and distribution of the particles were investigated by dynamic light scattering (DLS) (Malverm Instruments, Zetasizer). The specific surface area of the product was determined by Brunauer, Emmett and Teller (BET) method (Nanosord, S71).

For further evaluation of the process, 10 grams of HTV silicone was put in furnace at $700{ }^{\circ} \mathrm{C}$ for 5 minutes. The product was examined by XRD and BET according to the above mentioned condition.

\section{Results and discussion}

Results of the thermogravimetric analysis of HTV silicone are shown in Figure 1. TGA is a reliable technique that reveals the mass loss of substance during heating. It can be seen that HTV silicone has no weight loss up to $500{ }^{\circ} \mathrm{C}$, whereas from 500 to $650{ }^{\circ} \mathrm{C}$ weight loss of about $50 \%$ is observed. Continuation of heating above $700{ }^{\circ} \mathrm{C}$ has no effect on the weight. Therefore, TGA revealed that pyrolysis of HTV silicone was taken in the temperature range of $500-650{ }^{\circ} \mathrm{C}$. So the material was heated up to $700{ }^{\circ} \mathrm{C}$ at a heating rate of $20^{\circ} \mathrm{C} / \mathrm{min}$ in ambient atmosphere, and held at this temperature for an hour to fulfill pyrolysis and combustion. The product of this process was investigated as has been discussed here.

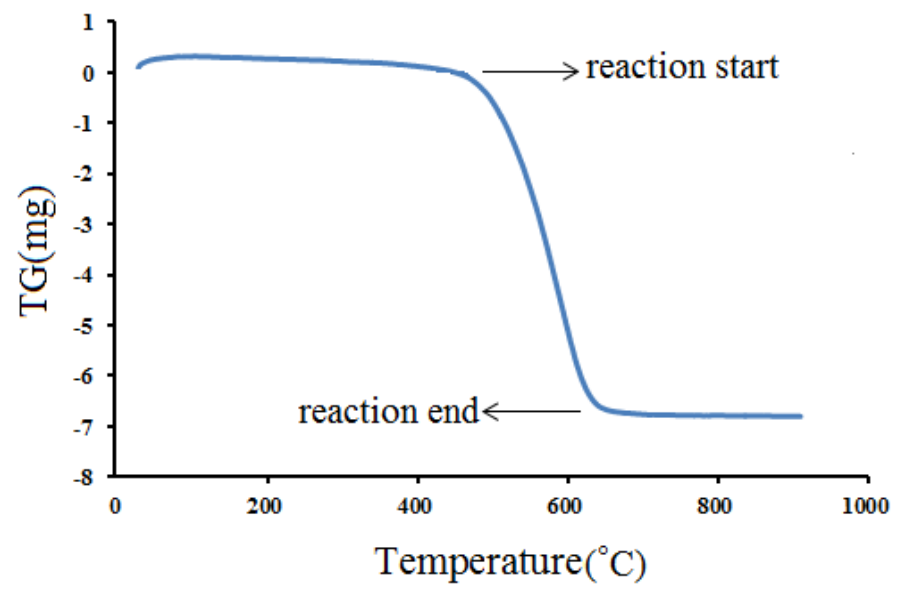

Fig. 1. TGA curve of HTV silicone with a heating rate of $10^{\circ} \mathrm{C} / \mathrm{min}$.

FESEM images of the product are shown in Figure 2. It is evident that the product is a very fine agglomerated powder made of nearly spherical particles. The dimensions of some of the particles are shown on the micrographs. It is confirmed that the product is a nanopowder, however, some additional studies is necessary to evaluate composition and dimension of it. 

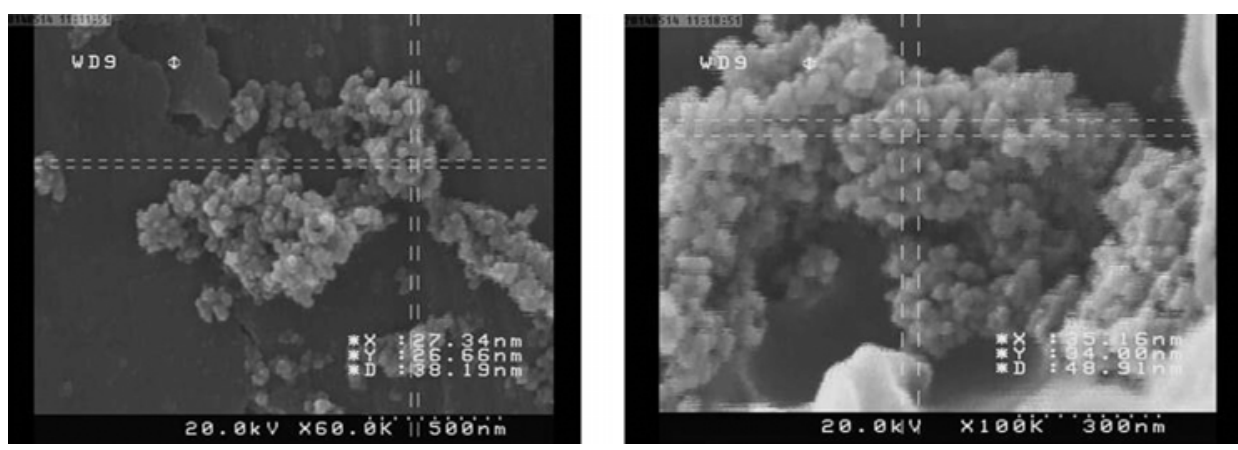

Fig. 2. FESEM images of pyrolyzed and combusted HTV silicone.

The size distribution of the particles was determined by DLS as shown in Figure 3. From the DLS results it appears that a great majority of the particles are between 100 and $200 \mathrm{~nm}$ in size which is not in agreement with FESEM micrographs. It should be kept in mind that in DLS test the powder particles are dispersed in a fluid by ultrasound. However, there is probability of agglomeration, particularly for nanopowders which have very high surface area and consequently total surface energy. Therefore, the curve in Figure 3 shows agglomerates size distribution instead of particles size, which will be confirmed by other tests in this paper.

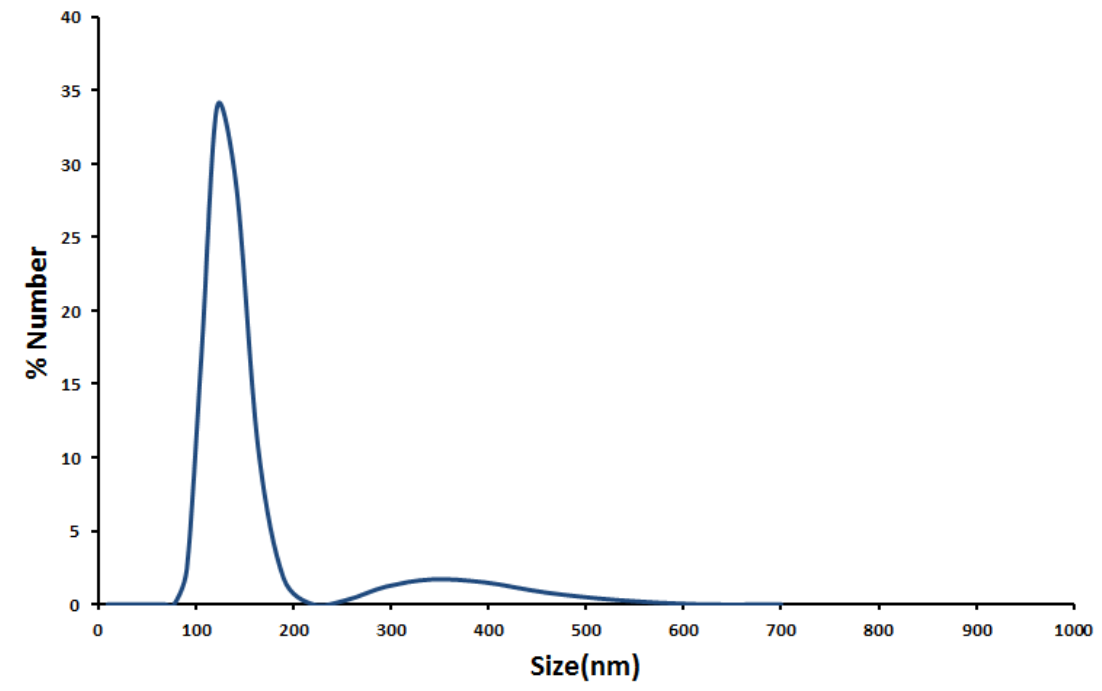

Fig. 3. DLS graph of pyrolyzed and combusted HTV silicone.

BET measurement of the powder showed a specific surface area of about 260 $\mathrm{m}^{2} / \mathrm{g}$. This is in the size range of nanopowders [26]. Based on this and FESEM images, it could be concluded that the product of pyrolysis and combustion of silicone HTV are nanoparticles.

X-ray diffraction pattern of the HTV silicone after pyrolysis and combustion is shown in Figure 4. A typical non-crystalline material diffraction pattern with a diffuse peak at around $22^{\circ}$ is visible which indicates that the synthesized material is amorphous. 
According to Adam et al. [15], the diffuse peak at $2 \theta$ of $22^{\circ}$ is the characteristic of silica phase.

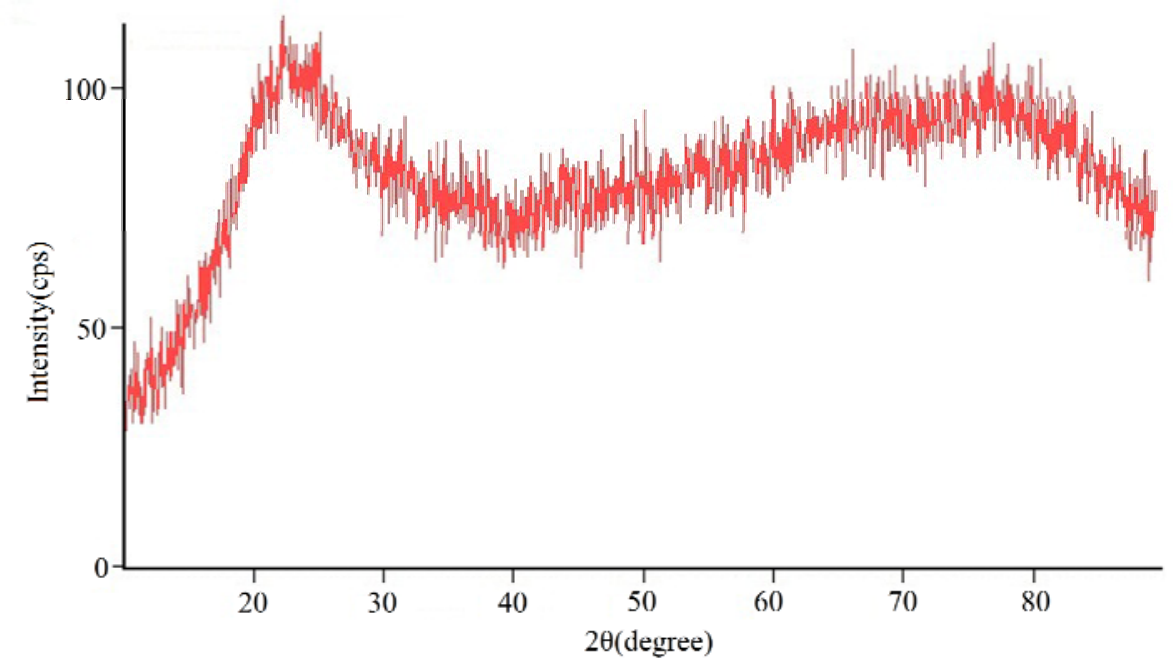

Fig. 4. XRD pattern of HTV silicone after pyrolysis and combustion.

To confirm abovementioned result of XRD, FTIR spectrum of the amorphous nanopowder is shown in Figure 5.

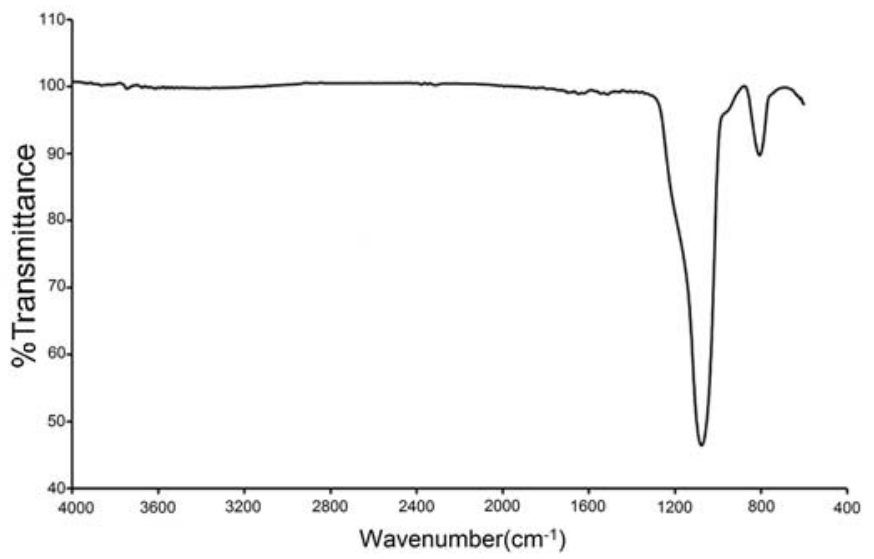

Figure 5. FTIR spectrum of the pyrolyzed and combusted HTV silicone

The peaks located at about $800 \mathrm{~cm}^{-1}$ and $1130 \mathrm{~cm}^{-1}$ are ascribed to stretching vibration of $\mathrm{Si}-\mathrm{O}-\mathrm{Si}$. This is consistent with the findings of $\mathrm{Gu}$ et al. [25]. Silica nanoparticles are often produced using chemical methods such as sol-gel. Therefore presence of absorbed hydrogen and carbon bonds from water, acids and bases, which decrease the purity of silica nanopowder, is expected in FTIR spectrum [17]. The FTIR 
spectrum of the product, in this study, indicates only $\mathrm{Si}-\mathrm{O}-\mathrm{Si}$ peaks, which means that the purity of the synthesized powder is very high. This is because no chemicals and additions like acid, bases and water have been used in the developed method.

The results of X-ray diffraction and FTIR spectrum analysis suggest that the synthesized powder is amorphous silica. Therefore, it is evident that the product of pyrolysis and combustion of HTV silicone is silica nanoparticle.

To verify previous findings, the powder particles were also examined with TEM. As shown in Figure 6, the silica particles in the product are spherical with a homogeneous particle size and shape distribution. The size of particles is in the range of $10-50 \mathrm{~nm}$ which is pretty smaller than the average size shown by the DLS analysis. As mentioned, this is due to the fact that in DLS test the powder is suspended in a liquid. This is believed to cause formation of agglomerates and increase the measured average particle size of the powder.
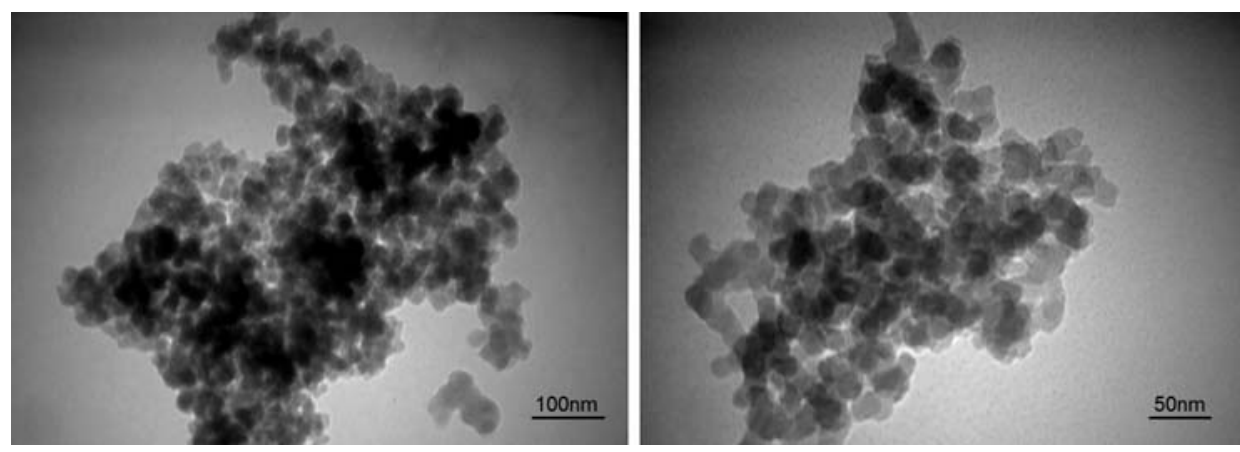

Fig. 6. TEM images of silica nanoparticles.

Mechanism of silica particles formation through pyrolysis of HTV silicone is by occurrence of two reactions during heating. In the first step (pyrolysis), the polymer decomposes to organic groups and silica as shown in reaction 1. In the second step (combustion), organic groups in the polymer react with oxygen in the atmosphere, and the gases are extracted from the particles (reactions 2 and 3). As an evidence for the second step of nanosilica synthesis a flare in the furnace is visible.

$$
\begin{aligned}
& \mathrm{C}_{5} \mathrm{H}_{12} \mathrm{Si}_{2} \mathrm{O}_{4} \rightarrow 2 \mathrm{SiO}_{2}+3 \mathrm{CH}_{2}+2 \mathrm{CH}_{3} \\
& 2 \mathrm{CH}_{2}+3 \mathrm{O}_{2} \rightarrow 2 \mathrm{CO}_{2}+2 \mathrm{H}_{2} \mathrm{O} \\
& 4 \mathrm{CH}_{3}+7 \mathrm{O}_{2} \rightarrow 4 \mathrm{CO}_{2}+6 \mathrm{H}_{2} \mathrm{O}
\end{aligned}
$$

FTIR spectrum confirms occurrence of these chemical reactions, without any indication of carbon and hydrogen bonds.

Major advantages of the described process for synthesis of silica nanoparticles in this study were short time, ease of fabrication and appropriate raw material. As pointed out in the introduction section, a number of techniques have been used for synthesis of silica particles. Sol-gel method, for instance, is a long and costly process. For instance, 
synthesis of silica nanoparticles by Le et al. [17] through sol-gel method took about 21 $\mathrm{h}$ and required solutions of a variety of acids and bases. In this study, however, the total time required for synthesis of silica nanoparticles including heating, isothermal holding and cooling, was $4 \mathrm{~h}$. No other consumables such as acidic or basic solutions are required and a scaled up fabrication is supposed to be easily achievable.

Product of pyrolysis of the sample at $700{ }^{\circ} \mathrm{C}$ for 5 min was also investigated by $\mathrm{XRD}$ and BET. The diffraction pattern is shown in Figure 7.

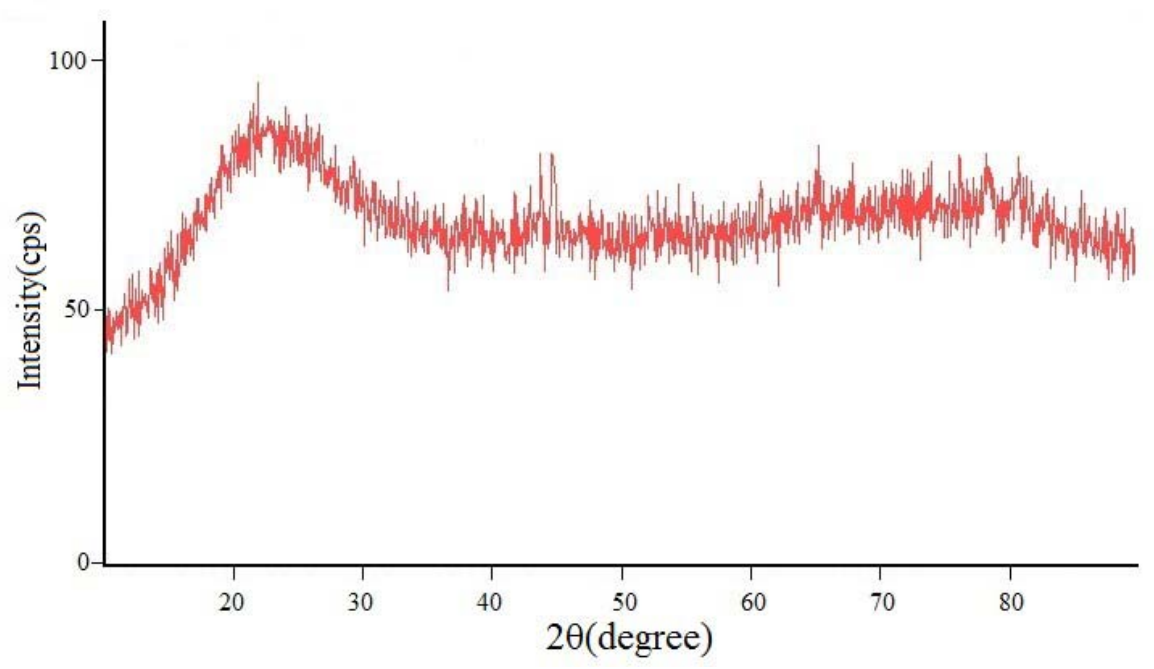

Fig. 7. XRD pattern of HTV silicone after pyrolysis and combustionat at $700{ }^{\circ} \mathrm{C}$ for $5 \mathrm{~min}$.

Similarly, there is a diffuse peak at $2 \theta$ of $22^{\circ}$ which is the characteristic of amorphous silica. Specific surface area of about $260 \mathrm{~m}^{2} / \mathrm{g}$ for the powder was measured by BET. Based on these investigations, it was concluded that silica nanoparticles could be produced by heating HTV silicone at $700{ }^{\circ} \mathrm{C}$ for $5 \mathrm{~min}$.

\section{Conclusions}

In this study a facile and novel method for synthesis of amorphous silica nanoparticles was introduced. Silica nanoparticles were produced by pyrolysis and combustion of HTV silicone at $700{ }^{\circ} \mathrm{C}$ for $1 \mathrm{~h}$, including heating up time from ambient temperature at heating rate of $20{ }^{\circ} \mathrm{C} / \mathrm{min}$. This was confirmed by XRD, DLS, FTIR, BET as well as FESEM and TEM examinations. XRD analysis revealed a diffuse peak at $2 \theta$ of $22^{\circ}$ matching that of amorphous silica. FTIR investigation showed the bonds in the synthesized material were of $\mathrm{Si}-\mathrm{O}-\mathrm{Si}$ bond. BET and DLS tests disclosed the average particle size of the product to be of nano order while FESEM and TEM analyses showed particle sizes in the range of 10-50 nm. The synthesized silicananoparticles are believed to be the product of reactions including decomposition of HTV silicone and combustion of the decomposed material in one stage and short time. 
It was also found that if the HTV silicone warms up instantly from ambient temperature process time of as short as $5 \mathrm{~min}$ is enough to obtain a similar product.

\section{References}

[1] K.R. Gopidas, J.K. Whitesell, M.A. Fox, Nano Lett. 3 (2003) 1757-1760.

[2] J. Jortner, C.N.R. Rao, Pure Appl. Chem. 74 (2002) 1491-1506.

[3] Y. He, H. Xu, H. Xu, S. Ma, P. Zhang, Mater. Lett. 131(2014)361-365.

[4] J.Ahmed, S.Sharma, K.V.Ramanujachary,S.Lofland, A. Ganguli, J. Colloid Interface Sci.336 (2009) 814-819.

[5] G.Couto, J.Klein, V.H.Schreiner, D.Mosca, A.Oliveira, ibid. Sci.311 (2007)461468.

[6] J.Zhang, Z.Dai, H.Bao, N.Zhang, M.Quintela, ibid. 305 (2007)339-344.

[7] Y.W. Baek, Y.G An, Sci. Total Environ. 409 (2011) 1603-1608.

[8] D. Hua, J. Tang, J. Jiang, Z. Gu, Mater. Chem. Phys. 114 (2009) 402-406.

[9] Q.He, J.Shi, J. Mater. Chem.21 (2011)5845-5855.

[10] L. Clement, A. Zenerino, C. Hurel, S. Amigoni, Sci. Total Environ. 450-451 (2013) 120-128.

[11] R. Yousefi, M.R. Muhamad, J. Solid State Chem. 183(2010)1733-1739.

[12] E. Effati, B. Pourabbas, Powder Technol. 246 (2013) 473-477.

[13] S. Pazokifard, S. Farrokhpay, M. Mirabedini, M. Esfandeh, Prog. Org. Coat. 87 (2015) 36-44.

[14] S. Alkis, F. Oruc, B. Ortac, A. Kosger, J. Optics.14 (2012) 125001.

[15] F.Adam, T.Chew, J.Andas, J. Sol-Gel Sci. Technol. 59 (2011)580-583.

[16] P.K.Jal, M.Sudarshan, A.Saha, A.Patel, B.K.Mishra, Colloids Surf., A240(2004)173-178.

[17] V.Le, C.Thuc, H.Thuc, Res Lett.8 (2013)58-68.

[18] Y.Liu, L.Zhang, X.Yao, C.Xu, Mater. Lett.49(2001)102-107.

[19] M.Santos, W.L.Vasconcelos, J. Non-Cryst. Solids.273(2000)145-149.

[20] Q.Ma, Y.Ma, Z.Chen, Ceram. Int.36 (2010) 2269-2272.

[21] P.Colombo, E.Bernardo, Compos. Sci. Technol. 63 (2003) 2353-2359.

[22] J.Zeschky, C.Arnold, M.Scheffler, P.Greil, Acta Mater.53 (2005)927-937.

[23] M.Wilhelm, C.Soltmann, D.Koch, G.Grathwohl, J. Eur. Ceram. Soc.25 (2005)271276.

[24] D.Li, S.Hwang, J. Appl. Polym. Sci.44 (1992)1979-1987.

[25] S.Gu, J.Zhou, Z.Luo, Q.Wang, M.Ni, Ind. Crop. Prod. 50 (2013)540-549.

[26] H.Jang, H.Oh, J.Kim, K.Jung, Microporous Mesoporous Mater.165 (2013)219227.

[27] Z.Peng, X.Fu, N.Zhu, X.Guo, C.Wang, J. Non-Cryst. Solids. 355 (2009)21562159.

[28] R.Madathingal, S.Wunder, Thermochim. Acta. 523 (2011)182-186.

[29] G. Lorenz, A. Kandelbauer, Thermoset PlasticsHandbook, third ed., Wiliam Andrew, New York, 2014. 